BENINNI, E.R.Y.; TAKAHASHI, H.W.; NEVES, C.S.V.J. Manejo do cálcio em alface de cultivo hidropônico. Horticultura Brasileira, Brasília, v. 21, n. 4, p. 605-610, outubro-dezembro 2003.

\title{
Manejo do cálcio em alface de cultivo hidropônico ${ }^{1}$
}

\author{
Elisabete R. Y. Beninni; Hideaki Wilson Takahashi; Carmen Silvia V.J. Neves
}

UEL, Depto. Agronomia, C. Postal 6001, 86.051-990 Londrina-PR; E-mail: beninni@sercomtel.com.br

\begin{abstract}
RESUMO
"Tipburn" ou "queima dos bordos" é um distúrbio fisiológico da alface ocasionado pelo suprimento inadequado de cálcio, principalmente nas folhas novas. Neste experimento foram avaliadas alternativas de manejo do fornecimento de cálcio, visando propiciar maior fluxo deste nutriente para as folhas internas de alface, cv. Vera, e consequentemente, reduzir a incidência de "tipburn". Foram testados cinco tratamentos dispostos em blocos, com cinco repetições:

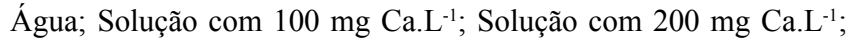
Aplicação foliar de cálcio ( 3 g.L $\left.\mathrm{L}^{-1}\right)$ e Completa (solução nutritiva completa). Os três primeiros tratamentos foram aplicados à noite para promover o desenvolvimento da pressão radicular e translocação do cálcio para as folhas internas; durante o dia circulava solução nutritiva completa em todos os tratamentos. Constatou-se que as plantas com maior desenvolvimento foram as mais suscetíveis ao aparecimento de "tipburn". O tratamento Solução com $200 \mathrm{mg} \mathrm{Ca.L^{-1 }}$ apresentou plantas com teor de cálcio superior aos demais tratamentos, porém a baixa incidência de "tipburn" durante o experimento dificultou a avaliação da eficiência dos tratamentos no seu controle. Mesmo os tratamentos que não receberam todos os nutrientes essenciais durante à noite não apresentaram deficiência nutricional e produziram plantas de peso adequado aos padrões de comercialização.
\end{abstract}

Palavras-chave: Lactuca sativa L., solução nutritiva; pressão radicular; tipburn.

\begin{abstract}
Calcium management in hydroponic lettuce

Tipburn is a physiological disorder in lettuce caused an by inadequate supply of calcium, mainly in young leaves. In this trial different management systems were evaluated in order to provide calcium and to increase the stream of calcium and reduce tipburn. Five treatments were studied in block design with five replications:

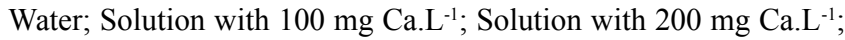
Spray calcium (3 g.. $\left.\mathrm{L}^{-1}\right)$ and Complete (complete nutrient solution). The three first treatments were applied at night to promote the root pressure and translocation of calcium to young leaves; during the day all treatments received a complete nutrient solution. More developed plants were more susceptible to tipburn. Solution with $200 \mathrm{mg} \mathrm{Ca} . \mathrm{L}^{-1}$ treatment increased the concentration of calcium in young leaves, but the low incidence of tipburn during the trial made the assessment of the treatments efficiency difficult. Even the treatments without all the essential nutrients during the night, didn't show nutritional deficiency and produced plants with suitable weight according to commercial standards.
\end{abstract}

Keywords: Lactuca sativa L., nutrient solution, root pressure, tipburn.

(Recebido para publicação em 03 de abril de 2002 e aceito em 30 de abril de 2003)

\begin{abstract}
$\mathrm{A}$ hidroponia é uma técnica alternativa de cultivo em que o solo é substituído por uma solução aquosa contendo elementos essenciais para o desenvolvimento da planta (Graves, 1983). No Brasil, tem crescido nos últimos anos o interesse por este cultivo, predominando o sistema NFT (nutrient film technique), ou fluxo laminar de nutrientes (Furlani et al., 1999), no qual as raízes ficam submersas em uma fina lâmina de solução nutritiva. A alface é a hortaliça mais cultivada neste sistema, representando $80 \%$ da produção hidropônica total (Furlani, 1999), devido à facilidade de cultivo, grande demanda pelo mercado e redução do período de cultivo (Gualberto et al., 1999). O melhor aspecto visual, a maior dura-
\end{abstract}

bilidade e a facilidade de limpeza têm contribuído para o aumento do consumo e da produção desta hortaliça (Ohse et al., 2001).

Um dos principais problemas enfrentados pelos produtores de alface, tanto de sistema hidropônico como convencional, é o aparecimento do "tipburn" ou "queima dos bordos", distúrbio fisiológico ocasionado pela deficiência localizada de cálcio (Collier \& Tibbitts, 1982), mesmo quando este elemento encontra-se em níveis adequados no solo ou solução nutritiva (Thibodeau \& Minotti, 1969; Ashkar \& Ries, 1971). A principal função do cálcio na planta é manter a integridade da parede celular (Malavolta, 1980) e o seu fornecimento inadequado é caracterizado pelo surgimento de necrose, principalmente nas extremidades das folhas em desenvolvimento (Collier \& Tibbitts, 1982).

Na planta, o cálcio move-se com a água, sendo sua translocação e seu teor nos tecidos sujeitos à taxa de transpiração (Collier \& Huntington, 1983). Uma vez depositado, não apresenta redistribuição para outras partes da planta, sendo acumulado principalmente em tecidos que transpiram mais facilmente (Millaway \& Wiersholm, 1979). Nos órgãos que apresentam dificuldade para transpirar, como as folhas novas e internas da alface, o transporte do cálcio é dependente das condições ambientais que favoreçam o desenvolvimento da pressão radicular (Bradfield \& Guttridge, 1984).

\footnotetext{
${ }^{1}$ Parte da dissertação de mestrado do primeiro autor, apresentada à UEL, Londrina, PR.
} 
A pressão radicular é um fenômeno que se desenvolve nas plantas quando a transpiração é reduzida a uma taxa menor do que a taxa de entrada de água pelas raízes (Tibbitts \& Palzkill, 1979), como ocorre durante a noite ou em períodos de alta umidade relativa do ar (François et al., 1991). Com a formação da pressão radicular, uma pressão positiva desenvolve-se no xilema causando fluxo do líquido no seu interior, podendo assim, translocar o cálcio para os órgãos com dificuldades para transpirar. A pressão radicular geralmente resulta em gutação (Tibbitts \& Palzkill, 1979).

Com base na pressão radicular, Bradfield \& Guttridge (1984) preveniram deficiência de cálcio em tomate e Van Berkel (1988) em repolho, mantendo alta umidade do ar durante a noite e baixa condutividade elétrica da solução nutritiva. Huett (1994) também verificou menor risco de "tipburn" quando a condutividade elétrica era 1,0 dS.m ${ }^{-1}$. Guttridge et al. (1984) reduziram a concentração da solução nutritiva durante a noite e verificaram maior teor de cálcio nas folhas em desenvolvimento, ocorrência de gutação e menor incidência de "tipburn" em plantas de morango. Creswell (1991) também verificou menor incidência de "tipburn" em alface quando substituiu, durante a noite, a solução nutritiva por água ou solução contendo somente cálcio.

Fatores que inibem o desenvolvimento da pressão radicular como seca, vento e alta salinidade promovem aparecimento de "tipburn" (Collier \& Tibbitts, 1982). Condições que favoreçam o rápido crescimento também aumentam a incidência (Thibodeau \& Minotti, 1969; Nagata \& Stratton, 1994). Desta forma, "tipburn" desenvolve-se rapidamente em plantas expostas à alta intensidade luminosa e extensos fotoperíodos (Gaudreau et al., 1994), alta temperatura do ar (Cox et al., 1976) e doses elevadas de adubação nitrogenada (Brumm \& Schenk, 1993).

O controle através da aplicação foliar de cálcio também foi estudado, porém os resultados nem sempre foram satisfatórios, como constatado por Van Berkel (1988), Johnson (1991) e Borkowiski \& Szwonek (1994), princi- palmente pela pulverização não alcançar as folhas mais suscetíveis, por ficarem encobertas por outras.

O objetivo deste experimento foi testar alternativas de manejo no fornecimento de cálcio, visando propiciar maior fluxo deste nutriente para as folhas internas de alface e consequentemente, reduzir a incidência de "tipburn".

\section{MATERIAL E MÉTODOS}

O experimento foi conduzido no sistema NFT (fluxo laminar de nutrientes), em ambiente protegido, na UEL. Utilizou-se alface tipo crespa, cultivar Vera. A semeadura foi realizada em bandejas de poliestireno expandido, tendo uma mistura de vermiculita e húmus como substrato. A irrigação foi feita diariamente. Após 20 dias, as plântulas foram retiradas das bandejas e na seqüência suas raízes foram lavadas com água para serem transferidas às canaletas de hidroponia, onde permaneceram até a colheita. O transplante ocorreu em 20/ 01 e a colheita em 23/02/01; durante esse período a temperatura dentro da estufa variou entre 19 e $39^{\circ} \mathrm{C}$.

Estudaram-se cinco tratamentos sendo eles: água(solução nutritiva completa durante o dia e água durante a noite), $100 \mathrm{Ca}$ (solução nutritiva completa durante o dia e solução contendo somente 100 ppm Ca durante a noite), $200 \mathrm{Ca}$ (solução nutritiva completa durante o dia e solução contendo somente 200 ppm de Ca durante a noite), aplicação foliar (solução nutritiva completa com aplicação foliar de cálcio) e Completo (solução nutritiva completa). As soluções noturnas foram aplicadas das 19:00 às 7:00 h. Utilizou-se nitrato de cálcio como fonte de cálcio para as soluções $100 \mathrm{Ca}$ e $200 \mathrm{Ca}$. No tratamento Aplicação foliar utilizou-se cloreto de cálcio na dose de 3 g.L L $^{-1}$, aplicados a cada dois dias e o tratamento Completo foi considerado como testemunha. Para preparar a solução nutritiva completa utilizou-se para cada litro de solução: $1 \mathrm{ml}$ de $\mathrm{KH}_{2} \mathrm{PO}_{4} \mathrm{M}, 5 \mathrm{ml}$ de $\mathrm{KNO}_{3} \mathrm{M}, 5 \mathrm{ml}$ de $\mathrm{Ca}\left(\mathrm{NO}_{3}\right)_{2} \mathrm{M}, 2 \mathrm{ml}$ de $\mathrm{MgSO}_{4} \mathrm{M}$, $1 \mathrm{ml}$ de Fe EDTA e $1 \mathrm{ml}$ de micronutrientes (composto por 2,86; 1,81; 0,$10 ; 0,04$ e 0,02 g.L ${ }^{-1}$ de $\mathrm{H}_{3} \mathrm{BO}_{3}$, $\mathrm{MnCl}_{2} \cdot 4 \mathrm{H}_{2} \mathrm{O}, \quad \mathrm{ZnCl}_{2}, \quad \mathrm{CuCl}_{2} \quad \mathrm{e}$
$\mathrm{H}_{2} \mathrm{MoO}_{4} \cdot \mathrm{H}_{2} 0$, respectivamente).

Cada bancada era constituída por três canaletas de PVC de $75 \mathrm{~mm}$ de diâmetro com 2,0 m de comprimento. As canaletas foram instaladas com uma declividade de $1,5 \%$ e comportavam um total de 20 plantas, com espaçamento de $0,20 \times 0,20 \mathrm{~m}$. As bancadas que necessitavam de trocas de soluções possuíam dois reservatórios, um para solução nutritiva completa e outro para o tratamento da noite. Cada reservatório possuía capacidade para 20 litros (1 litro por planta). A circulação da solução foi obtida mediante recalque com uma bomba de $32 \mathrm{~W}$, controlada por um temporizador que a mantinha $40 \mathrm{minu}-$ tos ligada e 10 minutos desligada das 10:00 h às 17:00 h (horário mais quente). Das 20:00 às 8:00 $\mathrm{h}$ permanecia 10 minutos ligada e 20 minutos desligada. No restante do tempo, permanecia 20 minutos ligada e 10 minutos desligada.

Quando ocorriam as trocas para as soluções da noite (19:00 h), as canaletas eram lavadas com água corrente, para evitar que a solução nutritiva completa contaminasse a solução da noite. $\mathrm{Na}$ manhã seguinte $(7: 00 \mathrm{~h})$ retornava a solução completa. Todos os tratamentos iniciaram-se duas semanas após o transplante.

Diariamente, todos os reservatórios de soluções nutritivas eram completados com água até 20 litros. $\mathrm{O} \mathrm{pH}$ das soluções era ajustado a uma faixa de 5,8 a 6,2, adicionando-se $\mathrm{HNO}_{3} 0,1 \mathrm{~N}$ ou $\mathrm{KOH} 0,1 \mathrm{~N}$, para reduzir ou elevar o $\mathrm{pH}$, respectivamente. As soluções nutritivas completas não eram trocadas, mas corrigidas, conforme o calendário de reposição de nutrientes recomendado por Suetake \& Takahashi (2000). As soluções $100 \mathrm{Ca}$ e $200 \mathrm{Ca}$ eram ajustadas com nitrato de cálcio quando abaixavam $30 \%$ da condutividade elétrica inicial.

$\mathrm{Na}$ colheita, as 15 plantas centrais de cada bancada foram separadas em folhas internas, folhas externas e raízes. Foram consideradas folhas internas as oito folhas mais novas de cada planta. Todas as partes foram lavadas em água corrente, pesadas e colocadas para secar em estufa com circulação de ar a $65^{\circ} \mathrm{C}$, até obtenção de peso constante. Posteriormente, o material seco foi moí- 
Tabela 1. Peso médio da matéria fresca e seca total (g.pl-1) e teor médio de nutrientes $\left(\mathrm{g} \cdot \mathrm{Kg}^{-1}\right)$ nas folhas externas e internas de plantas de alface, cultivar Vera, produzida em sistema hidropônico, sob diferentes tratamentos. Londrina, UEL, 2001.

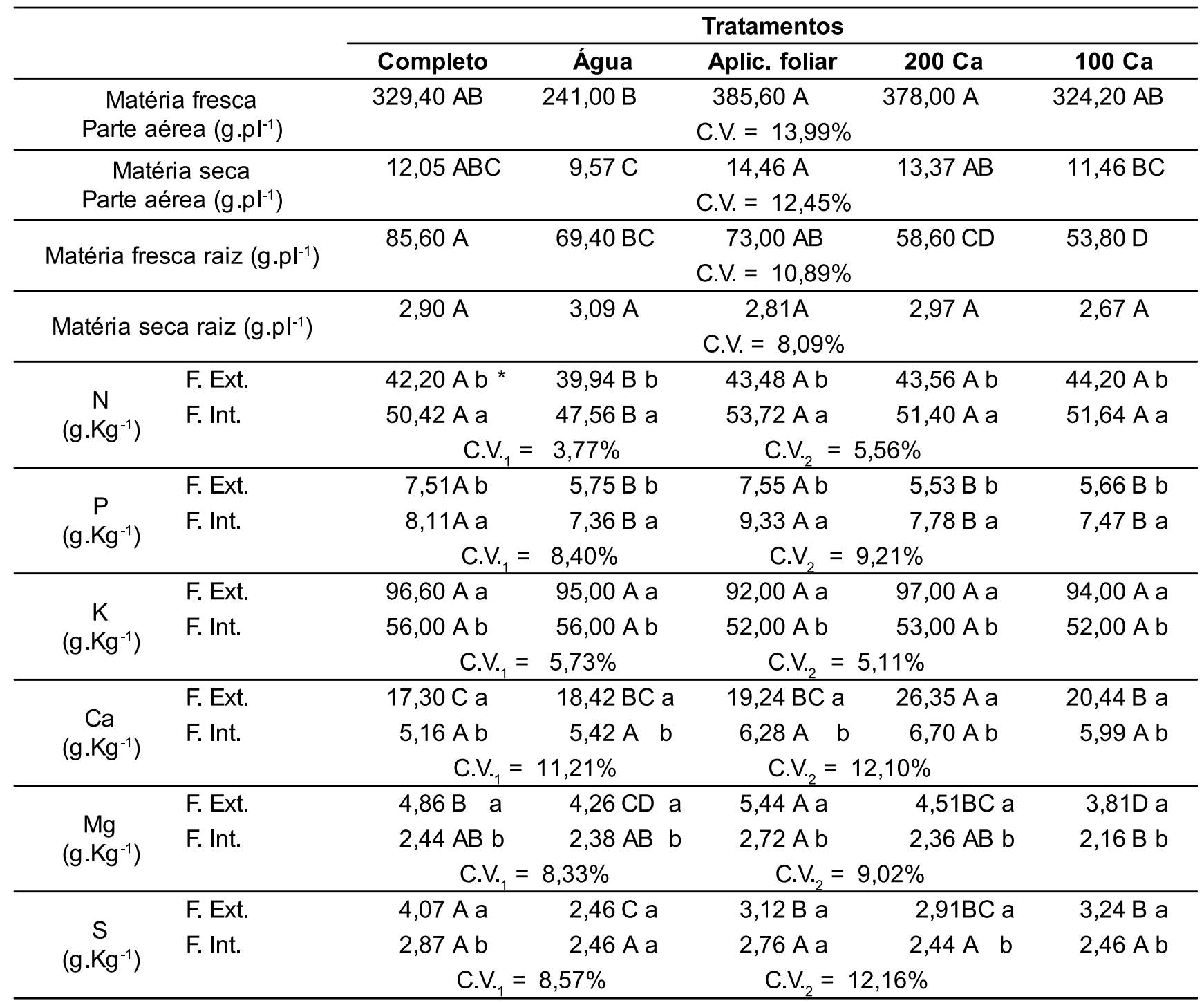

(*) Médias seguidas de mesma letra maiúscula na linha e minúscula na coluna não diferem entre si, pelo Teste de Tukey, ao nível de 5\%. C.V. $._{1}=$ Coeficiente de variação do tratamento principal (tratamentos); C.V. $._{2}=$ Coeficiente de variação do tratamento secundário (folhas externa e interna).

do e armazenado. Realizaram-se análises químicas para $\mathrm{N}, \mathrm{P}, \mathrm{K}, \mathrm{Ca}, \mathrm{Mg}$ e $\mathrm{S}$ das folhas internas e externas. Para a determinação do nitrogênio, foi feita a digestão sulfúrica e destilação pelo micro Kjeldahl. Para os demais nutrientes realizou-se digestão nítricoperclórica e a partir do extrato determinou-se cálcio e magnésio por absorção atômica, enxofre por turbidimetria de sulfato de bário, fósforo pelo método colorimétrico e potássio por fotometria de chama.

O delineamento experimental foi blocos casualizados. A análise estatística utilizada para os nutrientes foi em parcelas subdivididas em blocos sistemáticos, considerando como parcela principal os cinco tratamentos e como subparcela, as folhas internas e externas de plantas diferentes. Para as análises de peso e extração total de nutrientes consideraram-se somente as parcelas principais em blocos. Todas as análises possuíam cinco repetições e as médias foram comparadas pelo Teste Tukey a $5 \%$.

\section{RESULTADOS E DISCUSSÃO}

A incidência de "tipburn" foi baixa, mesmo sendo a alface cultivada duran- te o verão, época de maiores perdas de produção devido a esse distúrbio fisiológico. A suscetibilidade ao "tipburn" é determinada geneticamente (Saure, 1998), porém diversos fatores influenciam na sua ocorrência e intensidade (Brumm \& Schenk, 1993), variando de ano para ano, de local para local e mesmo dentro do período de crescimento. Saure (1998) comenta que por isso é difícil prever a sua ocorrência.

Nenhum dos tratamentos aplicados determinou aumentos significativos do teor de cálcio nas folhas internas das plantas de alface (Tabela 1), no entanto, o maior valor para essa variável foi ob- 
Tabela 2. Relação entre nutrientes em alface cultivar Vera, produzida em sistema hidropônico, sob diferentes tratamentos. Londrina, UEL, 2001.

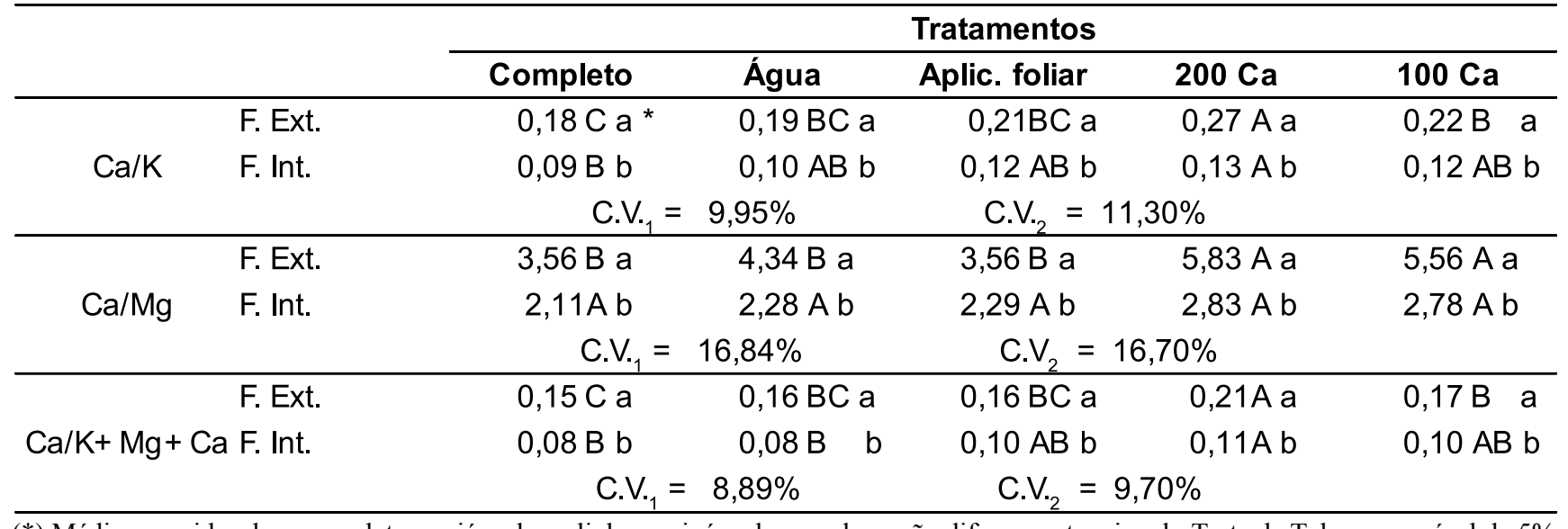

(*) Médias seguidas de mesma letra maiúscula na linha e minúscula na coluna não diferem entre si, pelo Teste de Tukey, ao nível de 5\%. C.V. $._{1}=$ Coeficiente de variação do tratamento principal (tratamentos); C.V. $._{2}=$ Coeficiente de variação do tratamento secundário (folhas externa e interna).

tido no tratamento $200 \mathrm{Ca}$ e o menor, no Completo. Creswell (1991) usando as mesmas concentrações, também verificou que os tratamentos com solução de nitrato de cálcio, fornecidos durante a noite, resultaram em plantas de alface com maiores quantidades de cálcio, porém, diferentemente deste experimento, o autor constatou uma relação entre quantidade de cálcio na folha e incidência de "tipburn".

Além dos teores superiores nas folhas internas, o tratamento $200 \mathrm{Ca}$ forneceu maiores quantidades de cálcio nas folhas externas (Tabela 1). Este resultado também pode ser visualizado nas relações $\mathrm{Ca} / \mathrm{K}$ e $\mathrm{Ca} / \mathrm{K}+\mathrm{Mg}+\mathrm{Ca}$ que foram significativamente superiores aos demais tratamentos (Tabela 2). $\mathrm{O}$ tratamento Completo apresentou as menores relações entre os nutrientes, demonstrando que o tratamento $200 \mathrm{Ca}$ proporcionou maior fluxo do cálcio, principalmente para as folhas externas, diferindo do resultado obtido por Creswell (1991) em que os aumentos no teor de cálcio ocorreu somente na parte interna das plantas de alface.

O teor de cálcio nas folhas externas (maior superfície de transpiração) das plantas de alface do presente trabalho, foi cerca de 3 a 4 vezes superior ao encontrado nas folhas internas (Tabela 1). Da mesma forma, Collier \& Huntington (1983), em seus estudos, concluíram que o transporte do cálcio é dependente da transpiração e, conseqüentemente, aquelas folhas que possuem maior superfí- cie de transpiração apresentaram maiores quantidades de cálcio.

A menor concentração de cálcio encontrada nas folhas internas foi $3,8 \mathrm{~g}$ $\mathrm{Ca} . \mathrm{Kg}^{-1}$ de matéria seca, sem apresentar sintomas visuais de deficiência de cálcio (dados não apresentados). Este resultado é contrário ao obtido por Ashar \& Ries (1971) que observaram sintomas visuais de deficiência de cálcio quando as plantas de alface possuíam 7,2 $\mathrm{g}$ $\mathrm{Ca} . \mathrm{Kg}^{-1}$ de matéria seca. Trabalhando com plantas de alface suscetíveis ao "tipburn", Huett (1994) verificou que o distúrbio ocorria quando o teor de cálcio nas folhas variava entre 1,7 e 3,2 g Ca. $\mathrm{Kg}^{-1}$ de matéria seca. Para Creswell (1991), a ocorrência de "tipburn" foi mais influenciada pela dificuldade de redistribuição do cálcio dentro da planta do que propriamente pela sua quantidade. Trabalhando com quantidades de cálcio somente em áreas foliares afetadas por "tipburn", Barta \& Tibbitts (2000) consideraram 0,2 a 0,4 g Ca. $\mathrm{Kg}^{-1}$ de matéria seca a faixa de teores críticos para sua incidência em alface, valores que ficaram bem abaixo dos encontrados pelos outros autores citados. Segundo esses autores, a análise de folhas inteiras pode mascarar os resultados, já que o distúrbio ocorre nas extremidades das folhas. Assim, grandes diferenças podem ser encontradas nos teores críticos de cálcio para incidência de "tipburn" quando se considera resultados obtidos por diferentes pesquisadores. Em função disso, a falta de correla- ção observada no presente trabalho, entre o teor de cálcio nas folhas internas e "tipburn", como no tratamento Completo, em que houve poucas plantas afetadas mesmo com os menores teores de cálcio nas folhas internas, pode estar associado à análise de folhas inteiras.

O tratamento Aplicação foliar resultou na produção de matéria fresca superior aos demais (Tabela 1), porém com visualização de sintomas leves de "tipburn". Esses sintomas podem estar relacionados ao maior desenvolvimento das plantas $(385,60 \mathrm{~g})$, já que no tratamento Água, que resultou nas menores plantas $(241,00 \mathrm{~g})$, o distúrbio não foi observado. Esses resultados estão de acordo com Gaudreau et al. (1994) e Nagata \& Stratton (1994) que verificaram que o "tipburn" desenvolveu-se mais rapidamente nas plantas que apresentavam altas taxas de crescimento. Thibodeau \& Minotti (1969) atribuíram este fato a um aumento na demanda de cálcio e sua insuficiente translocação para os locais de crescimento. Desta forma, verificou-se que a aplicação foliar de cálcio em alface, não é um método de controle eficaz, já constatado por Johnson (1991) e Borkowski \& Szwonek (1994), em cultivares que formam cabeça.

O magnésio e o potássio encontramse em maiores quantidades nas folhas externas (Tabela 1). Segundo Malavolta (1980), estes nutrientes também são transportados através do fluxo transpiratório porém, diferentemente do 
Tabela 3. Extração total de nutrientes (g.pl $\mathrm{l}^{-1}$ ) em alface cultivar Vera, produzida em sistema hidropônico, sob diferentes tratamentos. Londrina, UEL, 2001.

\begin{tabular}{|c|c|c|c|c|c|}
\hline \multirow{2}{*}{$\begin{array}{c}\text { Nutriente } \\
\left(\text { g.pl }^{-1}\right)\end{array}$} & \multicolumn{5}{|c|}{ Tratamentos } \\
\hline & Completo & Água & Aplic. foliar & $200 \mathrm{Ca}$ & $100 \mathrm{Ca}$ \\
\hline \multirow{2}{*}{ Nitrogênio } & $0,6040 \mathrm{AB}^{*}$ * & $0,3617 \mathrm{C}$ & $0,6545 \mathrm{~A}$ & $0,5836 \mathrm{AB}$ & $0,4843 \mathrm{BC}$ \\
\hline & & & C.V. $=15,18 \%$ & & \\
\hline \multirow{2}{*}{ Fósforo } & $0,1059 \mathrm{~A}$ & $0,0536 \mathrm{~B}$ & $0,1142 \mathrm{~A}$ & $0,0767 \mathrm{~B}$ & 0,0631B \\
\hline & & & C.V. $=18,09 \%$ & & \\
\hline \multirow{2}{*}{ Potássio } & $1,2735 \mathrm{~A}$ & $0,7528 \mathrm{~B}$ & $1,2610 \mathrm{~A}$ & $1,1861 \mathrm{~A}$ & $0,9372 \mathrm{AB}$ \\
\hline & & & C.V. $=16,52 \%$ & & \\
\hline \multirow{2}{*}{ Cálcio } & $0,2189 \mathrm{~B}$ & $0,1376 \mathrm{C}$ & $0,2554 \mathrm{AB}$ & $0,3075 \mathrm{~A}$ & $0,1939 \mathrm{BC}$ \\
\hline & & & C.V. $=17,68 \%$ & & \\
\hline \multirow{2}{*}{ Magnésio } & $0,0634 \mathrm{AB}$ & $0,0334 \mathrm{D}$ & $0,0738 \mathrm{~A}$ & $0,0549 \mathrm{BC}$ & $0,0389 \mathrm{CD}$ \\
\hline & & & C.V. $=17,49 \%$ & & \\
\hline \multirow{2}{*}{ Enxofre } & $0,0546 \mathrm{~A}$ & $0,0213 \mathrm{C}$ & $0,0442 \mathrm{AB}$ & $0,0372 \mathrm{~B}$ & $0,0346 \mathrm{BC}$ \\
\hline & & & C.V. $=18,33 \%$ & & \\
\hline
\end{tabular}

(*) Médias seguidas de mesma letra maiúscula na linha não diferem entre si, pelo Teste de Tukey, ao nível de 5\%.

cálcio, são móveis no floema, podendo ser redistribuídos pela planta quando ocorrer alguma deficiência. As folhas internas apresentaram teores de fósforo e nitrogênio superior às folhas externas (Tabela 1) provavelmente devido à alta mobilidade destes elementos no floema (Malavolta, 1980). O enxofre que possui circulação lenta, os maiores teores foram encontrados nas folhas externas (Tabela 1) possivelmente por estar retido em locais de síntese proteica e sua liberação só ocorre mediante a proteólise (Malavolta, 1980).

O tratamento Água apresentou extração de nutrientes inferior aos demais tratamentos (Tabela 3), porém, as plantas não apresentavam sintomas de deficiência nutricional. De acordo com Garcia et al. (2000), a extração de nutrientes em alface, cultivar Vera, em cultivo hidropônico foi: 0,$7057 ; 0,1066 ; 0,5582$; 0,$1559 ; 0,0379$ e $0,0386 \mathrm{~g}$ por planta de $\mathrm{N}, \mathrm{P}, \mathrm{K}, \mathrm{Ca}, \mathrm{Mg}$ e S, respectivamente. O tratamento Água também apresentou a menor produção de material fresco e seco (Tabela 1). A produção de matéria seca de alface, cultivada em sistema hidropônico obtida por Branco et al. (2000) variou de acordo com a época de plantio e cultivares avaliados. Quando o plantio ocorreu em janeiro, a produção de matéria seca da cultivar Vera foi 10,7 $\mathrm{g}$ por planta, valor que superou apenas o obtido no tratamento Água deste experimento (Tabela 1).
Pelo exposto, pode-se concluir que o tratamento $200 \mathrm{Ca}$ proporcionou maior fluxo de cálcio, tanto para as folhas externas como internas. Porém, a avaliação da eficiência dos tratamentos testados não pôde ser constatada devido à baixa incidência de "tipburn" durante o experimento. Apesar dos tratamentos Água, 100 Ca e 200 Ca não fornecerem, durante a noite, todos os nutrientes essenciais ao desenvolvimento das plantas, essas não apresentaram sintomas de deficiência nutricional, bem como possuíam peso comercial.

\section{AGRADECIMENTOS}

Os autores agradecem o apoio recebido pela Capes, através da concessão de bolsa de estudo.

\section{LITERATURA CITADA}

ASHKAR, S.A.; RIES, S.K. Lettuce tipburn as related to nutrient imbalance and nitrogen composition. Journal of American Society for Horticultural Science, v. 96, n. 4, p. 448-452, 1971. BARTA, D.J.; TIBBITTS, T.W. Calcium localization and tipburn development in lettuce leaves during early enlargement. Journal of American Society for Horticultural Science, v. 125, n. 3, p. 294-298, 2000.

BORKOWSKI, J.; SZWONEK, E. The effect of temperature on chinese cabbage tipburn and its control by calcium nitrate or citric acid. Acta Horticulturae, n. 371, p. 363-369, 1994.
BRADFIELD, E.G.; GUTTRIDGE, C.G. Effects of night-time humidity and nutrient solution concentration on the calcium content of tomato fruit. Scientia Horticulturae, v. 22 , p. 207-217, 1984.

BRANCO, R.B.F.; MAY, A.; SALATIEL, L.T.; PRESOTTI, L.E.; CAVARIANNI, R.L.; CECÍlLIO FILHO, A.B. Avaliação de cultivares de alface, cultivadas em hidroponia, em três épocas de plantio. Horticultura Brasileira, Brasília, v. 18, p. 701-702, 2000 (Suplemento).

BRUMM, I.; SCHENK, M. Influence of nitrogen supply on the ocurrence of calcium deficiency in field grown lettuce. Acta Horticulturae, n. 339, p. 126-136, 1993.

COLLIER, G.F.; TIBBITTS, T.W. Tipburn of lettuce. Horticultural Reviews, v. 4, p. 49-65, 1982. COLliER, G.F.; HUNTINGTON, V.C. The relationship between leaf growth, calcium accumulation and distribution, and tipburn development in field-grown butterhead lettuce. Scientia Horticulturae, v. 21, p. 123-128, 1983.

COX, E.F.; McFEE, J.M.T.; DERMAN, A.S. The effect of growth rate on tipburn occurrence in lettuce. Journal of Horticultural Science, v. 51, p. 297-309, 1976.

CRESWELL, G.C. Effect of lowering nutrient solution concentration at night on leaf calcium levels and the incidence of tipburn in lettuce (var. Gloria). Journal of Plant Nutrition, v. 14, n. 9, p. 913-924, 1991.

FRANÇOIS, L.E.; DONAVAN, T.J.; MAAS, E.V. Calcium deficiency of artichoke buds in relation to salinity. HortScience, v. 26, n. 5, p. 549-553, 1991.

FURLANI, P.R. Hydroponic vegetable production in Brazil. Acta Horticulturae, n. 481, p. 777-778, 1999.

FURLANI, P.R; SILVEIRA, L.C.P; BOLONHEZI, D.; FAQUIN, V. Cultivo hidropônico de plantas. Campinas, Instituto Agronômico, 1999, 52 p. (Boletim técnico, 180) 
GARCIA， N.C.P.; MARINALVA，W.P.; SEDIYAMA, M.A.N.; LIMA, P.C. Absorção de nutrientes por diferentes cultivares de alface em cultivo hidropônico no período de verão. Horticultura Brasileira, Brasília, v. 18, p. 246-247, 2000 (Suplemento).

GAUDREAU, L; CHARBONNEAU, J.; VÉZINA, L.P.; GOSSELIN, A. Photoperiod and photosynthetic photon flux influence growth and quality of greenhouse grown lettuce. HortScience, v. 29, n. 11, p. 1285-1289, 1994.

GRAVES, C.J. The nutrient film technique. In: JANICK, J. (Ed.) Horticultural Reviews. Westport, Connecticut: AVI, v. 5, cap. 1, p. 1-44, 1983.

GUALBERTO R.; RESENDE, F.V.; BRAZ, L.T. Competição de cultivares de alface sob cultivo hidropônico "NFT" em três diferentes espaçamentos. Horticultura Brasileira, Brasília, v. 17, n. 2, p.155-158, 1999.

GUTTRIDGE, C.G.; BRADFIELD, E.G.; HOLDER, R. Dependence of calcium transport into strawberry leaves on positive pressure in the xylem. Annals of Botany, v. 48, p. 473-480, 1984.
HUETT, D.O. Growth, nutrient uptake and tipburn severity of hydroponic lettuces in response to electrical conductivity and $\mathrm{K}: \mathrm{Ca}$ ratio in solution. Australian Journal of Agricultural Research, v. 45, p. 251-267, 1994.

JOHNSON, J.R. Calcium nutrition and cultivar influence incidence of tipburn of collard. HortScience, v. 26, n. 5, p. 544-546, 1991.

MALAVOLTA, E. Elementos de nutrição mineral de plantas. São Paulo: Agronômica Ceres, 1980, $251 \mathrm{p}$.

MILLAWAY, R.M.; WIERSHOLM, L. Calcium and metabolic disorders. Communications in Soil Science and Plant Analysis, v. 10, n. 1-2, p. 1-28, 1979.

NAGATA, R.T.; STRATTON, M.L. Development of an objective test for tipburn evaluation. Proceedings of Florida State Horticultural Society, v. 107, p. 99-101, 1994.

OHSE, S.; DOURADO NETO, D.; MANFRON, P.A.; SANTOS, O.S. Qualidade de cultivares de alface produzidos em hidroponia. Scientia Agricola, Piracicaba, v. 58, n. 1, 2001.
SAURE, M.C. Causes of the tipburn disorder in leaves of vegetables. Scientia Horticulturae, v. 76, p. 131-147, 1998.

SUETAKE, F.K.; TAKAHASHI, H.W. Calendário de reposição de nutrientes para alface (Lactuca sativa L.) em cultivo hidropônico. In: MOSTRA ACADÊMICA DE TRABALHOS DE AGRONOMIA, 4., 2000, Londrina. Resumos... Londrina: UEL, 2000, p. 100.

THibodeAU, P.O.; MinOtTI, P.L. The influence of calcium on the development of lettuce tipburn. Proceedings of the American Society Horticultural Science, v. 94, p. 372-375, 1969.

TIBBITTS, T.W.; PALZKILL, D.A. Requirement for root-pressure flow to provide adequate calcium to low-transpiring tissue. Communications in Soil Science and Plant Analysis, v. 10, n. 1-2, p. 251257, 1979.

VAN BERKEL, N. Preventing tipburn in chinese cabbage by high relative humidity during the night. Netherlands Journal of Agricultural Science, v. 36, p. 301-308, 1988. 